Volume 100 Number 3
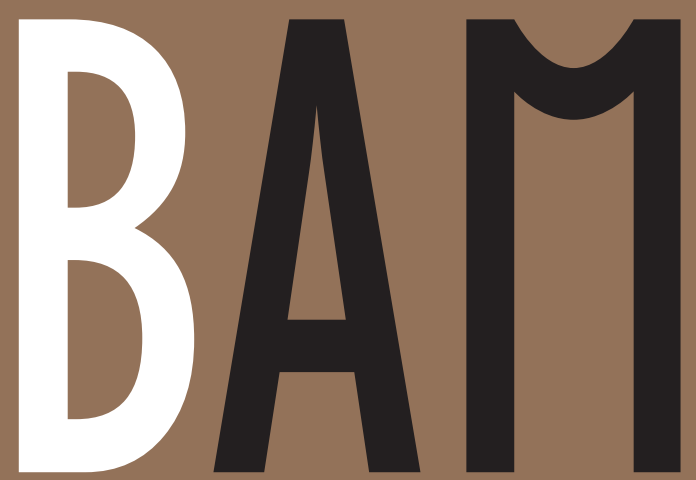

March 2019

Bulletin of the American Meteorological Society

\section{AUSTRALIA'S ENSO CHALLENGE}

THE DEPTHS OF HAIL

INTENSITY FORECAST SKILL

\title{
hav in the
}

Thitrd Pole

\section{A Multidisciplinary Approach to Tibet's Climate \& Environment}

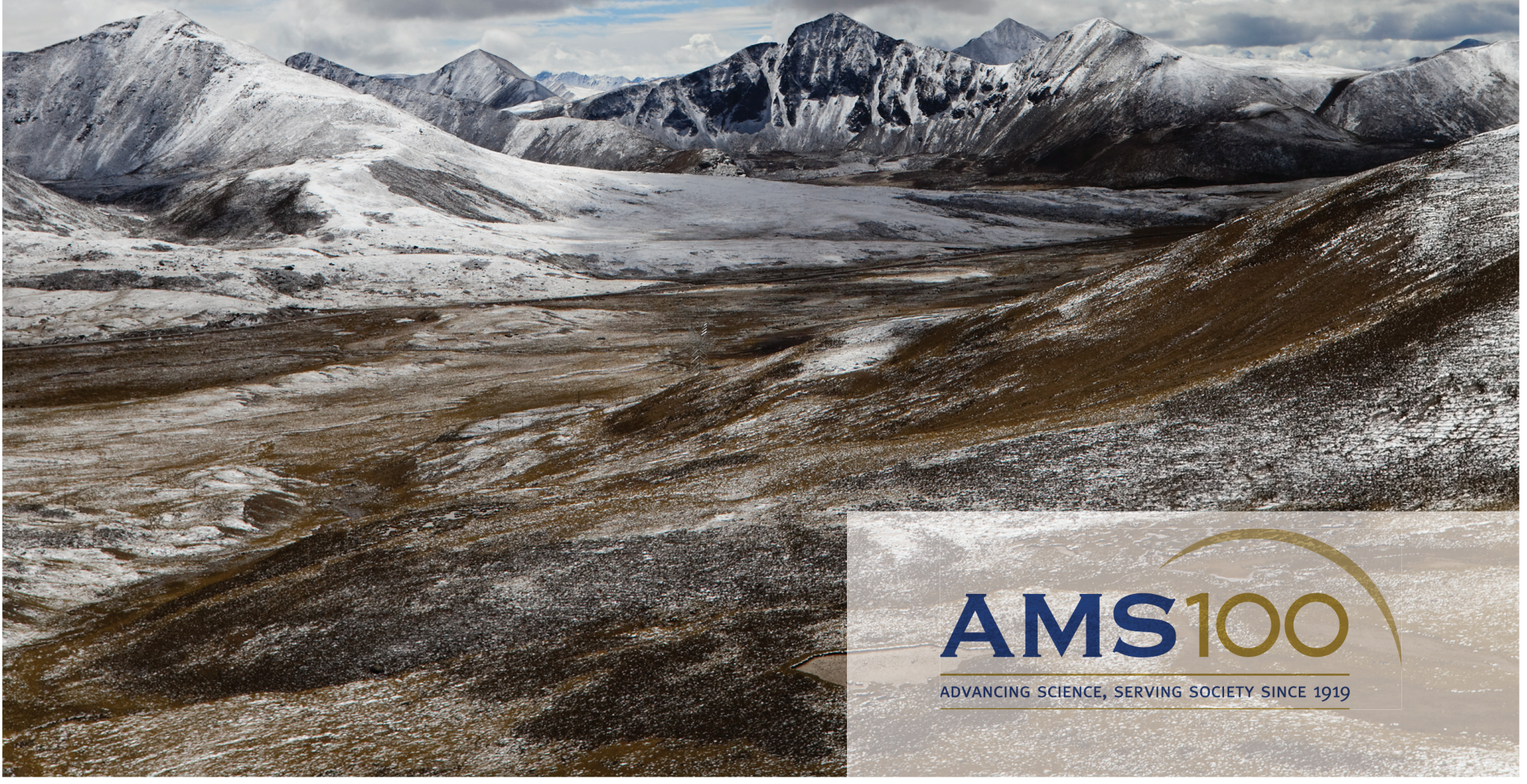

